\title{
PARADIGMAS E REVOLUÇÕES CIENTÍFICAS: A BATALHA ENTRE CIÊNCIA E PODER EM STAR TREK-VOYAGER
}

\author{
A. P. H.L. ÁVILA ${ }^{*}$, J. C. de MENEZES, L. L. C. L. MAIA e S. V. RODRIGUES \\ UNIFOR \\ paulahlima@gmail.com ${ }^{*}$
}

Artigo submetido em agosto/2014 e aceito em dezembro/2014

DOI: $10.15628 /$ holos.2014.2346

\section{RESUMO}

O presente artigo teve como objetivo analisar a representação da relação entre ciência e poder no episódio "A origem distante" da ficção televisiva Star Trek - Voyager. Para tanto, realizou-se uma pesquisa de natureza qualitativa, empregando-se com método o estudo de caso descritivo. Como técnica de coleta aplicou-se a observação não-participante, conforme Flick (2004). Já para o tratamento dos dados utilizou-se a análise do discurso de orientação francesa, conforme Gregolin (1995). Como resultado destaca-se a compreensão que os enunciados carregam significados e que, no caso em questão, o discurso televisivo reafirma a superioridade da ciência perante outros saberes. Assim, ciência e poder são representados através de uma analogia entre a obra de Galileu e a perseguição pela Inquisição. Essa relação é permeada pela resistência aos novos paradigmas, fazendo-se menção à ruptura com o senso comum, um dos obstáculos epistemológicos apontados por Bachelard (1996).

PALAVRAS-CHAVE: Poder, Paradigmas, Ciência, Análise do discurso.

\section{PARADIGM AND SCIENTIFIC REVOLUTIONS: THE BATTLE BETWEEN SCIENCE AND POWER IN STAR TREK - VOYAGER}

\begin{abstract}
This article aims to analyze the relationship between science and power in the episode "Distant Origin" of television fiction StarTrek - Voyager. It was made a qualitative research, using the descriptive method: case study, where collection techniques were applied to nonparticipant observation, FLICK (2005). In accordance with the data treatment was used discourse analysis of French orientation, GREGOLIN (1995). As a result it was possible to understand that the statements' meaning, in
\end{abstract}

this case, the televised speech reaffirms the superiority of science knowledge before others. Thus, science and power are represented by an analogy between the work of Galileo and persecution by the Inquisition. This relationship is permeated by the resistance to new paradigms, making up words to break with common sense, one of the epistemological obstacles mentioned by Bachelard (1996).

KEYWORDS: Power, Paradigm, Science, Discourse analysis. 


\section{INTRODUÇÃO}

A origem da vida humana é uma questão amplamente discutida ao longo dos anos. A teoria evolucionista de Charles Darwin, por exemplo, expressa uma quebra de paradigma com a teoria criacionista apresentada na Bíblia.

Thomas Kuhn em seu livro "A estrutura das revoluções científicas", defendeu que os paradigmas são "realizações científicas universalmente reconhecidas que, durante algum tempo, oferecem problemas e soluções modelares para uma comunidade de praticantes de uma ciência" (KUHN, 2005, p. 13).

O sentido do termo ciência sofreu algumas modificações ao longo dos anos. De acordo com Hühne (1990), a história revela grandes distinções entre a ciência na Renascença e na atualidade. Devido ao avanço tecnológico, houve, de fato, uma grande mudança no campo metodológico, e consequentemente, no campo da teoria científica. Essas transformações, sem dúvidas, foram ainda mais relevantes para a vida humana.

Este trabalho elegeu a narrativa seriada Star Trek - Voyager (Jornada nas estrelas) como objeto de análise. Mendonça e Guimarães (2007) consideram que o episódio A origem distante se utiliza de uma linguagem satírica para abordar como é construído o conhecimento científico. Propõe-se, portanto, como objetivo desta pesquisa: analisar a relação entre ciência e poder representada no referido episódio.

A batalha entre ciência e poder, no século XVII fez nascer uma nova visão de mundo, que tornou a ciência um elemento fundamental, forte e independente na história da humanidade (MAYOR; FORTI, 1998). Mesmo assim, a hegemonia e o respaldo social da ciência já foram postos em questão, visto que, a superioridade da ciência não é resultante apenas de pesquisas e debates, mais de coação institucionais e políticas (FEYERABEND, 2011).

Percebe-se, desse modo, que o progresso contínuo da ciência está interligado com as relações de poder existentes no campo científico. Em tempos atuais, principalmente devido à industrialização da ciência, as relações de poder podem ser vislumbradas nas esferas econômica, social e política, que passaram a ter um papel decisivo na definição das prioridades científicas (SANTOS, 1988). Assim, para compreender o panorama atual da ciência, faz-se necessário conhecer como o discurso televisivo contribui para a instituição da hegemonia do conhecimento científico.

Este artigo está estruturado da seguinte forma: Apresenta-se primeiramente a fundamentação teórica divida em dois tópicos: O nascimento da ciência moderna; e Paradigmas e as revoluções científicas. Subsequentemente, relatam-se os procedimentos metodológicos. Posteriormente, apresenta-se a análise observacional. E por fim, são tecidas as considerações finais.

\section{O NASCIMENTO DA CIÊNCIA MODERNA}

O mundo pós-moderno ainda vive sob a influência do Cientificismo, uma doutrina de caráter intelectual, que se caracterizou por associar o conhecimento verdadeiro ao conhecimento científico. Embora Platão e Aristóteles sejam citados como fundadores da ciência, 
sem dúvidas, o período Renascentista constitui uma das mais ricas épocas para o desenvolvimento da humanidade (HÜHNE, 1990).

O renascimento foi marcado por rupturas, inovações e o surgimento de uma nova era. Dentre os fatos que ocorreram nesse período, destaca-se o nascimento da ciência moderna com Galileu Galilei (HÜHNE, 1990).

Galileu Galilei é uma figura emblemática que participou de um dos maiores embates entre a ciência e o poder. Esse período da chamada revolução científica foi palco de algumas batalhas mais sangrentas da história, no qual poderosos líderes da Igreja repetidamente tentaram silenciar os pioneiros da ciência moderna (WHITE, 1896 apud NUMBERS, 2009).

"Galileu e seus sucessores consideravam a ciência moderna como uma ferramenta matemática para se descobrir a verdade absoluta da natureza" (MAYOR; FORTI, 1998, p.34). Dessa forma, para alcançar a verdade era preciso romper com os dogmas da Igreja, que, também, pode ser chamado de senso comum. Romper com o senso comum é considerado um obstáculo epistemológico por Bachelard (1996).

Kyoré (1951) apud Hühne (2009) defende que Galileu pode ser considerado o pai da ciência moderna ao diferenciar a linguagem específica da experimentação e a linguagem da experiência espontânea ao senso comum.

Esse fato, o fez ser condenado pela Inquisição e obrigado a renegar suas afirmações (SIMON, 2005).

\section{PARADIGMAS E AS REVOLUÇÕES CIENTÍFICAS}

A evolução do conhecimento científico não foi marcada apenas pelo crescimento, mas também, pelas inúmeras transformações, que por meio de rupturas possibilitou a passagem de uma teoria para outra. Deste modo, Morin (2003, p.22, grifo do autor) afirma que "as teorias científicas são mortais e 'são mortais' por 'serem científicas'".

O ensaio do filósofo Thomas Kuhn (2005) tem papel fundamental para compreender a provisoriedade do conhecimento científico. O autor demonstra a concepção da ciência normal. Naquele ensaio, o autor aborda questões fundamentais, como um momento que antecede a ciência, assim como, um momento pós-ciência; o surgimento de anomalias e quebra-cabeça; as revoluções representadas pelas crises e o surgimento de um paradigma que se estabelece como a ciência normal. Kuhn (2005, p. 13) considera o paradigma como "as realizações científicas universalmente reconhecidas que, durante algum tempo, fornecem problemas e soluções modelares para uma comunidade de praticantes de uma ciência".

Além disso, o progresso do conhecimento pode ocorrer em duas dimensões: no plano empírico, com as verdades; e no plano teórico, com a verificação e eliminação dos erros (MORIN, 2003). Esse pressuposto se aproxima da ideia de falseabilidade proposta por Popper (1998), isto é, "não basta que uma teoria seja verificável, é preciso que ela possa ser falsificada, isto é, que, eventualmente, se possa provar que ela é falsa" (MORIN, 2003, p.38). Feyerabend (2011) contesta o conhecimento sobre a ciência, ao acreditar que não há, ainda, conhecimentos, por mais modestos que sejam a respeito da ciência. "Não estamos muito longe da verdade quando dizemos que a natureza da Ciência ainda está envolta em escuridão" (FEYERABEND, 2011, p. 92). 
Quando um paradigma consegue chegar a um determinado status e é universalmente aceito por uma comunidade científica, esse estágio é denominado como Ciência Normal (KUHN, 2005). "'Ciência Normal' significa a pesquisa firmemente baseada em uma ou mais realizações científicas passadas. Essas realizações são reconhecidas durante algum tempo por alguma comunidade científica específica como proporcionando os fundamentos para sua prática posterior" (KUHN, 2005, p. 29, grifo do autor).

Existe a premissa de que a superioridade da ciência vai além da própria ciência. $O$ autor afirma que a ciência passou de uma instituição particular para parte do tecido básico da democracia, bem como a igreja em determinado período da história. "É claro, a Igreja e o Estado agora estão cuidadosamente separados. O Estado e a Ciência, no entanto, trabalham rigorosamente juntos" (FEYERABEND, 2011, p. 92).

Portanto, Feyerabend (2011) considera a Ciência como uma ideologia, mito, uma espécie de religião e que a mesma deve ser separada do Estado, pois em uma sociedade livre, todas as tradições têm direitos iguais e igual acesso ao poder. Fica evidente que o autor busca colocar no mesmo patamar que a ciência as outras tradições ao afirmar que: "a Ciência não se destaca em virtude de seu método, porque não há qualquer método; e não se destaca em virtude de seus resultados: sabemos o que a Ciência 'faz', mas não temos a menor ideia se outras tradições não poderiam fazer a mesma coisa 'muito melhor'" (FEYERABEND, 2011, p. 99, grifo do autor).

Em seguida, salientou o problema da objetividade. A objetividade dos dados que dão suporte a teorias, a objetividade da observação e a falseabilidade, são absolutas e incontestáveis. O que se contesta, é a teoria ser objetiva. "Uma teoria se fundamenta em dados objetivos, mas uma teoria não é objetiva em si mesma" (MORIN, 2003, p.40).

Igualmente, o problema do relativismo é discutido, e Feyerabend (2011) enxerga com bons olhos, pois acredita que o Relativismo poria fim a superioridade da ciência enquanto tradição aceita pela sociedade. "O Relativismo é atacado muitas vezes não porque encontramos uma falha nele, mas porque temos medo dele. Os intelectuais o temem porque ele ameaça seu papel na sociedade, assim como o lluminismo em uma época ameaçou a existência de padres e teólogos" (FEYERABEND, 2011, p. 99).

Além disso, argumentos metodológicos não estabelecem a excelência da Ciência. $O$ autor refuta a ideia de que a ciência é superior porque se utiliza de métodos corretos para obtenção de resultados e que existem muitas evidências que corroboram com a excelência do método. "Não existe nenhum "método científico"; não há nenhum procedimento único, ou conjunto de regras, que esteja presente em todas as pesquisas e garanta que é "científico" e, portanto, confiável" (FEYERABEND, 2011, p. 99).

Os paradigmas ganham esse status por conseguir responder e solucionar mais adequadamente alguns problemas tidos como graves pelos cientistas. "Contudo, ser bem sucedido não significa nem ser totalmente bem sucedido com um único problema, nem notavelmente bem sucedido com um grande número" (KUHN, 2005, p. 44).

Como um paradigma não consegue responder a todos os problemas e nem é necessário, contudo, ele precisa responder às questões mais relevantes abordadas. Quando isso não ocorre, surgem as revoluções científicas, "período durante os quais os paradigmas são primeiramente atacados e então modificados" (KUHN, 2005, p. 73). "A descoberta começa com a consciência da 
anomalia, isto é, com o reconhecimento de que, de alguma maneira, a natureza violou as expectativas paradigmáticas que governam a ciência normal" (KUHN, 2005, p. 78). "Para uma anomalia originar uma crise, deve ser algo mais do que uma simples anomalia" (KUHN, 2005, p. 113). No entanto, "uma teoria científica, após ter atingido o status de paradigma, somente é considerada inválida quando existe uma alternativa disponível para substituí-la" (KUHN, 2005, p. 107-108).

"A ciência é, portanto, elucidativa (resolve enigmas, dissipa mistérios), enriquecedora permite satisfazer necessidades sociais e, assim, desabrochar a civilização; é de fato, e justamente, conquistadora e triunfante" (MORIN, 2005, p. 15-16).

\section{METODOLOGIA}

O presente artigo tem caráter descritivo, uma característica intrínseca da abordagem qualitativa. Os métodos qualitativos além de admitir desvelar os processos sociais pouco conhecidos referentes a grupos particulares propicia a construção de novas abordagens, revisão e criação de novos conceitos durante a investigação (MINAYO, 2007). Além dessa característica, as pesquisas qualitativas não estudam as relações entre variáveis dependentes e independentes, como nas abordagens quantitativas, pois não objetiva testar hipóteses (STRAUSS, 2008).

Dentre as várias metodologias inerentes da pesquisa qualitativa, elegeu-se o estudo de caso descritivo. "O estudo de caso é caracterizado como 'descritivo' quando apresenta um relato detalhado de um fenômeno social que envolva, por exemplo, sua configuração, estrutura, atividades, mudanças no tempo e relacionamento com outros fenômenos" (GODOY, 2006, grifo do autor, p. 124).

Quanto a técnica de coleta, empregou-se, a observação indireta, não-participante, considerada de segunda-mão e proveniente de fotografias, vídeos ou filmes (FLICK, 2004).

Para Cooper e Schindler (2003), esse tipo de observação é menos flexível do que a observação direta, mas também pode ser mais acurada e muito menos tendenciosa, além de que através dessa técnica o registro permanente pode ser reavaliado para incluir vários aspectos diferentes do fato.

Para esta pesquisa, portanto, elegeu-se como objeto de análise o episódio "A origem distante" da narrativa seriada "Star Trek - Voyager". Desse modo, para a análise foi empregado o método da Análise do discurso de orientação francesa, conforme orientação de Gregolin (1995) e Charaudeau (2010). "O discurso construído pelo narrativo dá-se em dois níveis: uma 'estrutura lógica' subjacente à manifestação, espécie de espinha dorsal narrativa, e uma 'superfície semantizada' que se baseia na estrutura lógica e, ao mesmo tempo, joga com ela, a ponto de transformá-la" (CHARAUDEAU, 2010, p. 157, grifo do autor). Assim, para compreender o sentido construído através da narrativa, observou-se o referencial ao qual essa representação apoiou-se, como também, o universo narrado propriamente dito (encenação).

\section{DISCUSSÃO E RESULTADOS}

A série televisiva Star Trek - Voyager foi exibida nos Estados Unidos entre 1995 e 2001. Nesta obra de ficção são narradas as aventuras de uma tripulação na nave espacial U.S.S. 
Voyager em sua jornada no Quadrante Delta, em busca de uma maneira de retornar ao Quadrante Alfa, de onde desapareceram durante uma missão. Liderando a tripulação está a Capitã Kathryn Janeway, a primeira mulher a comandar uma nave da Federação em mais de 30 anos de história de Jornada nas Estrelas (MINHA SÉRIE, 2014). No episódio A origem distante, a tripulação da nave Voyager é capturada pelos sáurios da raça Voth.

No início do episódio o Professor Gegen e o seu discípulo Veer encontram um esqueleto humano. Essa descoberta faz os pesquisadores acreditarem que a origem de sua raça, os Voth, poderá ser finalmente explicada. Essa nova teoria, porém, refuta a crença da primeira-ministra Odala e dos poderosos anciões Voth, chamada de "A Doutrina", os quais acreditam serem os primeiros seres inteligentes do quadrante da galáxia. Isto se caracteriza como ciência normal, na qual existe, conforme Kuhn (2005) a existência de um paradigma vigente.

O estado de ciência normal conceituado por Kuhn (2005) é visualizado na cena na qual o professor Gegen e o seu assistente estão examinando o esqueleto humano que haviam encontrado. Os pesquisadores questionam o que o ser endotérmico (humano) estava fazendo em sua galáxia. A partir do levantamento de várias hipóteses, concluem a possibilidade de haver parentesco, mesmo que remoto da sua raça (Voth), com a raça encontrada daquele esqueleto analisado.

O enfoque positivista da ciência é visto em cenas, onde numa das quais, o professor Gegen afirma que o seu assistente, ao ingressar na sua equipe de pesquisa, assumiu a prerrogativa de perseguir a verdade científica. Mais claramente, na sociedade ocidental, a ciência é considerada a forma hegemônica de construção da realidade, ou seja, único meio de se encontrar a verdade. Porém, apesar de sua normatividade, o campo científico é permeado por conflitos e contradições, como por exemplo, o grande embate sobre a cientificidade das ciências sociais em comparação com as ciências da natureza (MINAYO, 2004).

De acordo com Gregolin (1995) a relação de oposição ou de diferença entre dois termos, dentro de um universo semântico, constitui a primeira parte do percurso de geração de sentido. Assim, ao longo do episódio foi observada a presença de valores fundamentais positivos (eufóricos) e negativos (disfóricos), conforme Quadro 01.

Quadro 01: Valores fundamentais positivos (eufóricos) e negativos (disfóricos)

\begin{tabular}{|c|c|}
\hline Verdade científica & Fantasia \\
\hline Verdade científica & Colorida história \\
\hline Provas & Pilha de ossos \\
\hline
\end{tabular}

Fonte: Elaborado pelos autores.

Em nível narrativo, segunda etapa do processo de geração de sentido, os valores fundamentais são narrados a partir de um sujeito (GREGOLIN, 1995). Assim, os sujeitos identificados como peças-chave foram: Pesquisador Gegen, Ministra Odala, Humano e a filha de professor Gegen. Conforme Gregolin (1995) a narrativa se constitui de quatro fases. Seguem:

a) MANIPULAÇÃO: o pesquisador Gegen e seu discípulo são manipulados pelas provas a tornar pública a descoberta;

b) COMPETÊNCIA: manipulado, os sujeitos precisam adquirir competência para realizar a ação. Essa competência, no episódio, seria o apoio do Conselho dos anciãos para examinar a nave dos humanos. Como não conseguiram, buscam o conselho de Exobiologia; 
c) PERFORMANCE: os sujeitos realizam a ação, ou seja, o Professor Gegen e o seu discípulo Veer vão examinar a nave para obter mais provas;

d) SANÇÃO: depois de realizada a ação, os sujeitos são recompensados (sanção positiva) ou punidos (sanção negativa). No episódio tanto o Professor Gegen quanto o seu discípulo Veer são punidos.

"O nível discursivo é o patamar mais superficial do percurso gerativo do sentido, o mais próximo da manifestação textual. As estruturas narrativas convertem-se em discurso quando assumidas pelo sujeito da enunciação" (GREGOLIN, 1995). Assim, percebeu-se que para demonstrar as relações de poder, foi evidenciada a questão da hierarquia. Os personagens que tornaram possível essa análise foram: Odala (Ministra dos anciãos Voth); Gegen (pesquisador); Veer (discípulo). Essa estrutura também foi percebida entre os humanos: Capitã Janeway; Primeiro oficial Chacotay e Tenente Paris.

Assim, considerando que "O DISCURSO é um suporte abstrato que sustenta os vários TEXTOS (concretos) que circulam em uma sociedade" (GREGOLIN, 1995) é possível analisar como o poder foi representado no episódio em questão.

Para obter a permissão para investigar a nave dos humanos, o professor Gegen e seu assistente se reúnem com a Ministra Odala para revelar a descoberta da origem da sua raça. 0 diálogo a seguir mostra a reação da Ministra Odala ao perceber que o paradigma vigente está sendo questionado.

Gegen: Por milhões de anos, nosso povo acreditou que éramos os primeiros seres inteligentes a evoluir nesta região do espaço, a primeira raça. Esta premissa permeia tudo que nos é mais caro. Mas esta crença tem sido questionada nos últimos anos, não apenas nos meios científico e filosófico, mas pelas pessoas comuns também. Deitada à sua frente está a prova da Teoria da origem distante. Esses restos mostram, sem dúvidas, que surgimos em algum outro lugar nesta galáxia, que evoluímos em um planeta distante e viajamos há milhões de anos atrás para este espaço. Nossa história perdida.

Odala: Uma pilha de ossos. Impressionante.

Gegen: Essa "pilha de ossos" pertenceu a um ser de uma espécie inexistente no espaço conhecido que morreu aproximadamente há um ano. E, mesmo assim, compartilhamos 47 marcas genéticas com esse ser. Somos indubitavelmente aparentados a ele. Eu pretendo Ihe provar, que evoluímos no mesmo planeta que ele.

Odala: Esse seria o planeta perdido da Teoria da origem Distante.

Gegen: Sim. Exatamente isso. E para encontrar tal planeta, nosso planeta, temos que encontrar um membro vivo dessa espécie. Criamos uma extrapolação por computador. Procuramos uma raça de bípedes endotérmicos viajantes, mas tecnologicamente limitados. Baseado na sua capacidade craniana, diria que não são mais avançados que a maioria dos endotérmicos.

Odala: Endotérmicos?

Assistente de Odala: Está sugerindo que somos aparentados com uma espécie mamífera?

Gegen: Sim. É por isso, que peço sua permissão para lançar uma expedição... 
Odala: Vamos falar sobre a sua descoberta. Gostei da colorida história que você encontrou nesses restos. Aqui diz que você pagou uma soma substancial por sua localização.

Gegen: Estava lidando com comerciantes. Eles conheciam a localização da caverna. Não tive escolha.

Odala: Você já considerou a possibilidade de ter sido vítima de um trote?

Gegen: Eu analisei cada mícron desse esqueleto. Eu asseguro que é autêntico.

Odala: Professor Gegen, você já considerou as amplas implicações de sua... teoria?? Por desafiar a Doutrina, você está sugerindo que tudo em que acreditamos sobre nós mesmos, nossa história, nossa antiga e justa reivindicação por esta região do espaço, a própria autoridade deste ministério é uma mentira?

Gegen: Não é o que estou dizendo. Entretanto, sob a luz da minha descoberta, algumas de nossas crenças devem ser reavaliadas.

Odala: Reavaliadas? Nós... consideraremos sua solicitação por uma expedição.

A ministra é severamente crítica fazendo uma analogia dos achados de Gegen com uma colorida história, algo lúdico, uma grande brincadeira, chamando a sua descoberta de "uma pilha de ossos". Percebe-se, portanto, uma relação de poder presente no diálogo comentado anteriormente. Esse diálogo remete a alguns fatos que se tornaram conhecidos sobre as descobertas da origem humana. Quando a ministra Odala e o seu assistente se surpreendem perante a afirmação de parentesco entre os Voth e a espécie mamífera, observa-se que esse texto fundamenta-se no discurso do parentesco entre os humanos e os macacos. A raça Voth, assim como a raça humana demonstra que possui recursos tecnológicos avançados, porém, no que se refere à sua origem, ainda prefere manter seus dogmas.

Na cena seguinte, percebe-se que o enunciador deixa claro seu posicionamento, através da fala de Gegen em diálogo com o seu discípulo Veer.

Gegen: Falhei em antecipar o nível de ignorância que encontraria. Quero que marque uma reunião com o círculo de exobiologia ${ }^{1}$. Temos apoio lá.

Na cena seguinte, o professor Gegen conversa com a sua filha:

Filha: Eu acho que eles não foram muito receptivos.

Gegen: Eles não precisam ser. As evidências falarão por si próprias. E as notícias da minha descoberta já estão se espalhando. Se gente suficiente confrontar o Ministério...

Filha: Matemática nunca foi seu ponto forte, pai. Você deve estar superestimando seu apoio.

Gegen: Você também não acredita em mim?

Filha: Eu quero acreditar, mas... Nossos ancestrais vieram de algum outro lugar. Nós não pertencemos a este lugar? Isso tudo parece tão, inacreditável.

Gegen: Estou desapontado com você.

Filha: Você está perseguindo uma fantasia. E está desperdiçando sua genialidade.

\footnotetext{
${ }^{1}$ Ramo da biologia que estuda a vida extraterrena.
} 
Esse diálogo aborda alguns pontos interessantes da pesquisa científica. Quando o professor Gegen fala - as evidências falarão por si próprias - e sua filha diz - matemática nunca foi seu ponto forte - esse discurso remete ao positivismo e ao conhecimento lógico e matemático como uma forma de alcançar a verdade (GEWANDSZNAJDER, 2001).

Através do discurso de Gegen, percebe-se que as estruturas narrativas transmitem o sentido de que a humanidade viverá na ignorância, caso não supere seus "mitos ancestrais".

Baseando-se na premissa de que a verdade deve ser conhecida, a contestação do paradigma dominante ganha força com o surgimento de anomalias. Conforme a literatura, as anomalias são responsáveis por novas versões e surgimento de novas teorias. Assim, as anomalias que surgiram no filme foram: evidência de um fóssil de um mamífero, uniforme que continha informações de origem e as 47 marcas genéticas semelhante com os sáurios. "Para aceitar como paradigma, uma teoria deve parecer melhor que suas competidoras, mas não precisa (e de fato isso nunca acontece) explicar todos os fatos com os quais pode ser confrontada" (KUHN, 2005, p. 38).

Percebem-se semelhanças entre a trajetória de Gegen e do pai da ciência moderna Galileu Galilei. Segue uma das cenas que evidencia essa analogia:

Veer: Precisamos ir agora. Eu me reuni com o Círculo de exobiologia e eles estão preocupados. Tem havido rumores...

Gegen: Sobre o que?

Veer: O Ministério apreendeu sua pesquisa e planejam prendê-lo.

Gegen: Sobre que acusação?

Veer: Heresia contra a Doutrina.

Gegen: Eu me defenderei.

Veer: É tarde demais. Seus apoiadores estão amedrontados. Ninguém vai the apoiar.

Gegen: Eu terei que fazer isso sozinho, então.

A atividade científica desenvolve-se a partir de inquietações do pesquisador acerca do objeto. Segundo Gewandsznajder (2001), isto quer dizer que os interesses do pesquisador guia como será feita a observação, a coleta de dados e as experiências.

Gegen: Vamos aprender um pouco mais observando-os. Quando tivermos reunido às informações necessárias, e se eles não forem violentos, faremos contato. Vamos procurar em seu banco de dados, analisar seu comportamento, qualquer coisa que possa nos dizer quem e o que estas pessoas são. Olhos abertos, Veer.

Através das observações foi diagnosticada uma hierarquia matriarcal, personificada na figura da capitã. Nota-se também no filme, a relação de poder e hierarquia exercida pelo professor com relação ao seu discípulo Veer, e da ministra, com relação aos demais.

Gegen: Bem, Veer, o que pode observar sobre sua estrutura social? É obviamente hierárquica, com claras diferenças de status e posição. Os machos parecem ser subordinados aquela fêmea. Talvez um matriarcado. 
Ao retornar de sua expedição, Gegen é acusado por heresia contra a doutrina e posteriormente, Odala questiona se o pesquisador deseja retirar sua alegação sobre a Teoria da origem distante. Após a negação deste, a ministra enfatiza que o citado professor anteriormente já havia proferido duras críticas a Doutrina, através de um estudo, a que denominou "Resistência à verdade".

A ministra Odala afirma que através da publicação do estudo, era possível identificar que estava sendo feita uma crítica aos anciões e mesmo sem o autor mencionar a palavra "Doutrina" suas intenções eram claras. Essa cena também faz menção a Galileu Galilei, o qual publicou a obra Dialogo sopra i due massimi sistemi del mondo (Diálogo sobre os dois principais sistemas do mundo), que foi decisiva para que a Inquisição o caçasse.

O humano capturado como prova, revela que o banco de dados da Voyager - nave tripulada por humanos - contempla um acervo completo dos fósseis da terra ao longo da sua história, porém a ministra argumenta que os dados não estão em questão, mas sim a sua interpretação. Isso demonstra que os dados em si podem assumir várias perspectivas, o que dará uma conotação ou outra é o olhar do pesquisador.

Odala, ao final, induz de forma contundente, que o professor, em nome da liberdade dos humanos, abra mão da sua teoria e omita os dados coletados importantes, desconsiderando a emergência de um novo paradigma.

Gegen: Você faria qualquer coisa para me silenciar. Bem, não vai funcionar. Nunca renegarei minhas alegações. Prefiro ir para prisão a ajuda-la a perpetuar a ignorância!

Odala: Você renega suas alegações?

Gegen: Não. Eu as mantenho.

Odala: Muito bem. É meu julgamento e você vai sofrer as consequências de sua obstinação. Gegen, você é culpado de heresia contra a Doutrina e irá ser colocado em uma Colônia de detenção. Enquanto respirar, não ensinará nem pesquisará. Sua vida como cientista terminou.

Gegen: Como desejar.

Odala: Chakotay da nave estelar Voyager, você, sua capitã e sua tripulação se juntarão ao prof. Gegen.

Gegen: Por que? Você não tem o que ganhar com a prisão deles. Deixe-os ir.

Odala: Vocês passarão o resto de suas vidas em uma colônia de detenção. Sua nave será destruída. Você entregará sua nave imediatamente e informará sua tripulação que este julgamento.

Gegen: Pare, por favor!!

Odala: Você está me oferecendo uma alternativa?

Gegen: eu... reconsiderarei e renego minhas alegações com respeito à Teoria da origem distante. Minha análise dos dados era obviamente falha. Eu estava... errado.

Odala: Está preparado para refutar seu trabalho publicamente ante o Círculo das ciências?

Gegen: Sim. 
Seguindo o pensamento de Charaudeau (2010), essa narrativa pode ser classificada como do tipo que idealiza heróis. Gegen é proposto como um modelo, um arquétipo de um ideal de ser (CHARAUDEAU, 2010). O desfecho da história, no qual Gegen retira suas alegações para salvar os tripulantes da nave Voyager evidencia a conduta heroica do personagem. Esse desfecho da narrativa também remete à história de Galileu Galilei, que foi condenado pela Inquisição e obrigado a renegar suas alegações (SIMON, 1990).

\section{CONSIDERAÇÕES FINAIS}

O presente estudo teve como objetivo analisar a representação da relação entre ciência e poder no episódio "A origem distante" de ficção televisiva Star Trek - Voyager. Assim, antes de tecer as considerações acerca dessa representação é interessante ressaltar que a narrativa evoca dois paradigmas muito relevantes para a história da humanidade: o nascimento da ciência moderna com Galileu Galilei e a teoria evolucionista de Charles Darwin.

A ciência é representada na narrativa como a verdade absoluta, sem a qual os indivíduos estão com os "olhos fechados". O poder que age contra a ciência é representado com algo que impede o processo de evolução dos indivíduos, encarcerando-os na eterna ignorância. Algumas marcas presentes no enunciado, como a expressão "olhos abertos" pode ser considerada uma forma de chamar a atenção do telespectador para o que está sendo falado. Também, constitui uma marca que posiciona as ideologias do autor, ou seja, de quem escreveu a narrativa.

A representação da relação entre ciência e poder é permeada pelo discurso de "resistência à verdade". A postura da Ministra Odala constitui uma representação da resistência à quebra de paradigmas, remete, também, a batalha para romper com o senso comum. Ressaltando que romper com o senso comum é considerado um obstáculo epistemológico por Bachelard (1996).

A batalha entre a ciência e o poder, constitui uma representação da trajetória do homem que fez grande descobertas astronômicas - Galileu Galilei. Na narrativa, Gegen, Veer e os tripulantes da Voyager representam a ciência. Já a Doutrina é uma representação da Igreja, enquanto que o Ministério dos anciãos, liderado por Odala, remete à Inquisição.

Observou-se, um discurso que defende uma visão maniqueísta, no qual a ciência representa o bem e a doutrina representa o mal. Observou-se, também, que a fim de convencer o enunciatário de que essa visão constitui-se verdade, a narrativa traça um tênue panorama entre um paradigma que superou os obstáculos e conseguiu se estabelecer (heliocentrismo de Copérnico e os achados de Galileu) e outro que embora tenha grande aceitação da comunidade científica, ainda é questionado pela massa (Darwinismo).

Percebe-se, portanto, que o discurso analisado reforça a ideia de superioridade da ciência, abordando-a como um "saber imaculado" (GUSDORF, 1976), sem o qual a sociedade é refém da ignorância.

Vale ressaltar, entretanto, que a própria ciência constitui-se um meio de poder (GUSDORF, 1976). A ideia de superioridade da ciência e sua associação ao bem geral, também, é questionada por Feyerabend (2011). O autor afirma que a ciência passou de uma instituição particular para parte do tecido básico da democracia, bem como a igreja em determinado 
período da história. "É claro, a Igreja e o Estado agora estão cuidadosamente separados. O Estado e a Ciência, no entanto, trabalham rigorosamente juntos" (FEYERABEND, 2011, p. 92).

Diante das conjunturas teóricas que fundamentaram a análise, percebe-se que o discurso midiático constrói-se para manter a ciência como elemento fundamental para a evolução da humanidade.

\section{REFERÊNCIAS}

1. BACHELARD, G. A formação do espírito científico: Contribuição para uma psicanálise do conhecimento. Rio de Janeiro: Contraponto, 1996.

2. CHARAUDEAU, Patrick. Linguagem e discurso: modos de organização. 2. ed. São Paulo: Contexto, 2010.

3. COOPER, D. R.; SCHINDLER, P. S. Métodos de pesquisa em Administração. Porto Alegre: Bookman, 2003.

4. FEYERABEND, P. K. A Ciência em uma Sociedade Livre. São Paulo: Editora Unesp, 2011.

5. FLICK, U. Uma introdução à pesquisa qualitativa. Porto Alegre: Bookman, 2004.

6. GEWANDSZNAJDER, F. Uma visão geral do método nas Ciências Sociais. In: ALVES-MAZOTTI, A. J.; GEWANDSZNAJDER, F. O método nas Ciências Naturais e Sociais - Pesquisa Quantitativa e Qualitativa. 2. ed. São Paulo: Pioneira Thompson Learning, 2001.p.3-54.

7. GODOY, A. A. Estudo de caso qualitativo. In: GODOI, C.K.; BANDEIRA-DE-MELO, R.; SILVA, A. B. da. (Org.). Pesquisa qualitativa em estudos organizacionais: Paradigmas, Estratégias e métodos. São Paulo: Saraiva, 2006. p.115-146.

8. GREGOLIN, Maria do Rosário Valencise. A análise do discurso: conceito e aplicações. Alfa, São Paulo, (39): 13-21, 1995.

9. GUSDORF, G. Galileu e o advento da ciência moderna. In: HÜHNE, L.M. (Org.). Metodologia Científica: Caderno de Textos e Técnicas. Rio de Janeiro: Agir, 1990.

10. HÜHNE, L.M. (Org.). Metodologia Científica: Caderno de Textos e Técnicas. Rio de Janeiro: Agir, 1990.

11. KUHN, T. S. A Estrutura das Revoluções Científicas. 9. ed. São Paulo: Perspectiva, 2005.

12. MAYOR, Federico; FORTI, Augusto. Ciência e poder. Campinas, SP: Papirus; Brasília: UNESCO, 1998.

13. MENDONCA, J. Ricardo C. de; GUIMARAES, Flávia Peixoto. Do quadro aos "quadros": o uso de filmes como recurso didático no ensino de administração. Cadernos EBAPE, Rio de Janeiro v. 6, n. esp, Ago. 2008. Disponível em: $<$ http://www.scielo.br/scielo.php?script=sci_arttext\&pid=S167939512008000500003\&lng=en\&nrm=iso>. Acesso em 07 Ago. 2014.

14. MINAYO, M.C. de S. O desafio do conhecimento. São Paulo: Hucitec, 2007.

15. Pesquisa social: teoria, método e criatividade. 23. ed. Petrópolis, RJ: Vozes, 2004.

16. MINHA SÉRIE, Star trek - Voyager. Disponível em: http://www.minhaserie.com.br/serie/187- 
star-trek-voyager. Acesso em: 11 ago. 2014.

17. MORIN, E. Ciência com Consciência. 7. ed. Rio de Janeiro: Bertrand Brasil, 2003.

18. NUMBERS, Ronald L.. Mitos e verdades em ciência e religião: uma perspectiva histórica. Rev. psiquiatr. clín., São Paulo , v. 36, n. 6, 2009 Disponível em: < http://www.scielo.br/scielo.php?script=sci_arttext\&pid=S010160832009000600006\&lng=en\&nrm=iso>. Acesso em 12 Ago. 2014.

19. SANTOS, Boaventura de Sousa. Um discurso sobre as ciências na transição para uma ciência pós-moderna. Estud. av., São Paulo, v. 2, n. 2, Ago. 1988. Disponível em: $<$ http://www.scielo.br/scielo.php?script=sci_arttext\&pid=S010340141988000200007\&lng=en\&nrm=iso>. Acesso em 07 Ago. 2014.

20. SIMON, M. C. Galileu Galilei. In: HÜHNE, L. M. da (Org.). Metodologia científica - caderno de textos e técnicas. 4. ed. Rio de Janeiro: Agir, 1990.

21. STRAUSS, A; CORBIN, J. Pesquisa Qualitativa: Técnicas e procedimentos para desenvolvimento da teoria fundamentada. Porto Alegre: Artmed, 2008.

\section{AGRADECIMENTOS}

Agradecemos à FUNCAP (Fundação Cearense de Apoio ao Desenvolvimento Científico e Tecnológico) pelo suporte financeiro. 